\title{
A Critical Analysis of Bloom's Taxonomy in Teaching Creative and Critical Thinking Skills in Malaysia through English Literature
}

\author{
Shukran Abdul Rahman ${ }^{1} \&$ Nor Faridah Abdul Manaf ${ }^{1}$ \\ ${ }^{1}$ International Islamic University Malaysia, Malaysia \\ Correspondence: Nor Faridah Abdul Manaf, International Islamic University Malaysia, Malaysia. E-mail: \\ nfaridah@iium.edu.my
}

Received: August 2, 2017 Accepted: August 22, 2017 Online Published: August 24, 2017

doi: 10.5539/elt.v10n9p245 URL: http://doi.org/10.5539/elt.v10n9p245

\begin{abstract}
Purpose: The study aims to (1) review the literature that analyses the relevance of Bloom's Taxonomy of Educational Objectives in the teaching of creative and critical thinking among students in Malaysia, and (2) identify missing aspects in Bloom's Taxonomy vis a vis the indigenous context, important to promote creative and critical thinking among students in Malaysia.

Method: Multiple sources of information which (1) documents the objectives of English Literature curriculum in Malaysia, (2) outlines the nature of Bloom's Taxonomy, (3) reports past research which addresses issues in the application of Bloom's Taxonomy, and (4) reports research findings on the issues in teaching English Literature as a subject.

Findings: The literature subject is an essential avenue for students' learning, especially in developing creative and critical thinking. The English syllabus with augmented taxonomy should be based on holistic learning outcomes which contain three set of abilities- Rationale Thinking, Purposeful Thinking, and Effective Relation with Contexts.

Significance: The study would shed light on the effectiveness of teaching creative and critical thinking through English Literature. The findings may help curriculum developers and teachers to explore the missing aspects in the Bloom's Taxonomy vis a vis the indigenous context, hence lead to the development of informed way forward in designing effective pedagogical approach/es that nurture creative and critical thinking among students.
\end{abstract}

Keywords: bloom's taxonomy, taxonomy of learning outcomes, creative thinking, critical thinking, English literature

\section{Introduction}

The Government of Malaysia through the Ministry of Education has put in place an education system which aims to develop individuals with essential competencies that enable them to become good citizen and workforce for the country. The trajectory of education in Malaysia includes curriculum and co-curricular activities which equip students with necessary knowledge, skills, norms, values, cultural elements and beliefs. The competencies are enabling competencies which would make them sagacious individuals for the current and future world of work, and community (Ministry of Education, 2012). The Malaysian Education Development Plan has outlined six aspiration- leadership skills, dual-language skills, spiritual development and ethics, social identity, useful knowledge, and thinking skills which would enable students to survive in the increasingly competitive markets.

The holistic education programme is based on the National Education Policy which necessitates education to be a continuous effort to develop the potential of individuals through a holistic and integrated approach. The aim of education in Malaysia is to produce individuals who have balanced competencies substantiated by four core components; intellectual, spiritual, emotional and physical capacities. The education system is developed based on a firm belief in and devotion to God (Akta Pendidikan 1996 (Akta 550), Peraturan-peraturan dan kaedah-kaedah terpilih sehingga 5 Januari 2013 (ms12). (MoE, 2012).

In Malaysia, the English language subject is taught both at the school and university levels. At school, it is a compulsory subject in the national curriculum at the primary, and secondary schools. It is accorded as an important second language in the Education Ordinance since 1957, the Education Act (GoM, 1961 and 1996) and the 1970 National Education Policy (MoE, 2012). Among the objectives of English language curriculum is 
to equip students with the basic skills and knowledge of the English Language which would enable them to have effective oral and written communication when they are in and out of the school (MoE, 1983 and 2001).

Recent education reform in Malaysia witnessed the introduction of the new Primary School Standards-Based Curriculum for English language education (SBELC) in 2011 (Hazita, 2016). Paramjit Kaura, Nooraida Mahmor (2014) stated that the Malaysian Education Blueprint has made it imperative that all children in Malaysia are proficient in Bahasa Malaysia and the English language (National Education Blueprint, 2012, E-10). Among the strategies to enhance the English Language proficiency among students is the expansion of the English Language subject to include compulsory English Literature component at the secondary school level.

In the Malaysian primary and secondary school curriculum, English literature is expected to serve as a study and resource. In the context of English Language as a subject in Malaysian schools, literature serves as a resource which provides the avenue to promote English language learning, helping students improve their proficiency in the language. It has been adopted as a mechanism to enhance and upgrade students' proficiency level of English; and develop their personal characters. As a study, the English Literature subject is expected to provide students with the exposure to other cultures and world views. Studying and reading literature material will enable them to expand their view of the world (Ganakumaran, 2003).

\subsection{The Problem}

There are a number of challenges confronting the teaching of literature in Malaysian schools. Among the issues raised was on the extent of learning outcomes attained by the students, particularly when it concerns the adaptation of curriculum which stresses the attainment of Higher Order of Thinking Skills or HOTS, derived from the Bloom's Taxonomy of Cognitive Learning objectives (Malachi Edwin Vethamani, 2003).

The Bloom's taxonomy has been around since 1956, and later revised in 2001 by Anderson L.W. et al). There are numerous criticisms on both original and revised Bloom's taxonomies, but none had looked beyond evaluating students' thinking processes. Furst (1994), for example, pointed out that the taxonomy oversimplified the nature of thinking and its relationship to learning. Since Bloom's taxonomy is widely used in Malaysian teaching curricula especially in testing and evaluating students' performances, it is important to critically analyse the loopholes of Bloom's taxonomy and study its relevance in a culture which is significantly different from that of where it was created for.

The HOTs which have been used in assessing students' achievement in the English literature component of the English paper has received criticisms in that the focus is only on higher-order thinking skills. There were reports about the challenges faced by many Malaysian students who suffer from learning difficulties either for literature component in the English Language subject (Suliman \& Yunus, 2014), or the English Literature subject (Ashairi $\&$ Melor, 2014).

Search in the literature data base shows the absence of research that studies as to how would students attain the high thinking level if they have difficulties to understand the material they read. This research is hence undertaken to review the tool -The Bloom's Taxonomy- which has influenced teaching philosophies around the world especially in promoting critical and creative thinking, often focusing on the higher-order thinking skills. Specifically, this research was conducted to answer the following questions (1) Is Bloom's Taxonomy relevant to be the bases of learning creative and critical thinking skills in English literature subject?, (2) Why is it important to incorporate certain values lacking in Bloom's Taxonomy e.g. religiosity, or culture?, and (3) What are the salient components that substantiate creative and critical thinking skills in English literature classes to suit the local culture? The main purpose of the study were (i) to analyse Bloom's Taxonomy and study its relevance in the teaching and learning of English Literature, and (ii) to explore the missing aspects in Bloom's Taxonomy vis a vis the indigenous context, important to promote creative and critical thinking among students.

\subsection{Significance of the Research}

The study is important for a number of reasons. Firstly, the findings on the relevance of adopting the Bloom's Taxonomy in the teaching and learning of English Literature in Malaysia would shed light on the reasons for the low level of effectiveness in the teaching of creative and critical thinking. Secondly, the findings may help curriculum developer and teachers to explore the missing aspects in Bloom's Taxonomy vis a vis the indigenous context, important to promote creative and critical thinking among students. It is expected that the findings would inform curriculum developers on the way forward in promoting heightened interest and engagement with the subject among students. The findings could be a good basis to formulate an alternative to the Bloom's Taxonomy of educational objectives. 


\section{Literature Review}

A review of the literature on the topics-in-question was conducted. The data gathered were synthesized to respond to the questions extrapolated in the above section. The findings were also used to shed lights on the missing areas that require improvement in the existing methods. The following sections summarize the review which respond to the research questions.

\subsection{The Bloom's Taxonomy}

Bloom's Taxonomy of Educational Objectives is a classification system by an educational psychologist, Benjamin Bloom who created it in 1956. The aim was to make students aware of what they were learning, hence striving to attain more sophisticated levels of learning with six cognitive-learning categories. It focuses on developing thinking ability which involves simple information acquisition to more complex processes (Bloom, 1956). Adams (2015) summarises the six levels of Bloom's taxonomy of cognitive learning objectives as (1) Knowledge, which entails foundational cognitive skill that require students to retain of specific, discrete pieces of information, (2) Comprehension, which requires students to paraphrase the content of knowledge in their own words, classify items in groups, compare and contrast items with other similar entities, or explain a principle to others, (3) Application, entailing students to use knowledge, skills, or techniques in new situations, (4)Analysis, which requires students to distinguish between fact and opinion and identify the claims upon which an argument is built, (5) Synthesis, which entails the need to create a novel product in a specific situation, and (6) Evaluation, which requires students to critically appraise the validity of a study and judge the relevance of its results for application.

The Bloom's Taxonomy of Educational Objectives has been regarded for a long time as an important tool for cognitive development. It has influenced many teaching philosophies around the globe especially in promoting rational thinking, often focusing on higher-order thinking skills. The taxonomy was later revised in 2001 by Anderson. However, it prompted further criticisms and is regarded as the most catastrophic framework in education (Case, 2013). Case highlights that the taxonomy limits students' capability to think beyond a sequence given and he gives a comment by a teacher as an example: "My student struggle with comprehension and recall, how can I expect them to tackle application and evaluation?" (p. 3). He believes that any misapplication of Bloom's taxonomy as a theory of teaching is often used to justify reduced expectations of students' capacity to think.

The following section will look at how English Literature used to enhance creative and critical thinking skills and gauge if Bloom's Taxonomy is still relevant to promote such skills.

\subsection{Relevance of the English Literature Subject in the Teaching and Learning of Creative and Critical Thinking Skills}

In answering a question on whether the Bloom's Taxonomy is relevant to be the bases of learning creative and critical thinking skills in the English literature subject, there are a number of pertinent questions to be attended. First, what is involved in the teaching and learning of English Literature? Do students engage in simple information acquisition or complex thinking processes, the former is a reflection of low order thinking, and the latter for the higher order thinking.

The teaching and learning of English Literature fosters creative and critical thinking skills. Defined as the ability to interpret facts, apply generalisations, and recognize errors (D'angelo, 1970) critical thinking requires students to use content of knowledge that he or she deals with in order to better understand something he or she does not know yet. It also involves the effort to seek for more information that require him or her to ask questions, and come up with the answer of solutions on what he or she was asking for (Elias, 2014).

The subject is taught in schools with the aim to develop students' ability in determining the ways to search for the meaning of life (Chambers \& Gregory, 2006). The subject provides the meaning of life by including the ideas on moral and social issues (D'Angelo, 1970). This enables them to differentiate between moral and immoral conducts (D'Angelo, 1970). They are taught to understand important aspects of life (Chambers, \& Gregory, 2006); to give attention to certain aspects of life, or ignore specific phenomena (Chambers, \& Gregory, 2006); and to think of the aspects of life that deserve acknowledgement or admiration (Chambers, \& Gregory, 2006).

Norling (2009) outlines several aims and objectives in the teaching of English literature at upper secondary school. Among the objectives are to improve students' ability to read literature in English with good understanding as well as to reflect over texts from different perspectives. The teaching of literature gives students the opportunity to develop understanding of life, foster toleration, develop moral standards, as well as 
instill positive affects between humankind and nature. The teaching of literature would foster ideas or theories about human nature and conduct, define moral attitudes, and habitual responses to people and situations. Besides, it also exposes students to the language and the culture which the literary material portrays.

When teaching literature, the aim is often to nurture thinking. Students should be coached to attempt the reading comprehension questions in order to verify their understanding of the text; learn to detect their weaknesses in logical reasoning; conduct group presentations to enhance their abilities in synthesis, organization, communication and cooperation; be guided in-class discussion with questioning skills to provoke their critical thinking; and be required to attempt individual essay-question reports to promote deductive or inductive reasoning and organization (Tung \& Chang, 2009). Teachers' competency in teaching skills in classroom is crucial in order to foster the development of thinking skills among the students because they can improve their thinking skills if their teachers teach them how to think.

The subject exposes and enthuses students with the experiences of others who stay in other places or different time (Chambers \& Gregory, 2006); and stimulates them to appreciate the experience. The subject also encourages students to creatively work on alternative direction of life, and assess the implications associated with it (Chambers \& Gregory, 2006).

The subject provides platforms for students to understand the aspects of English culture as written in the text. They would study the allusions and references to different aspects of English culture (Smith, 2005; Norling, 2009). The subject too provides an alternative to the pervasiveness or commonness of "television culture" which is associated with shallowness in its content so much so that it provides less impact on education (Smith, 2005).

Table 1. Aspects of creative and critical thinking in learning and teaching English literature vis a vis the Bloom's Taxonomy of Cognitive Learning

\begin{tabular}{lll}
\hline Ability set & Components & $\begin{array}{l}\text { Bloom's Level of } \\
\text { Cognitive learning }\end{array}$ \\
\hline
\end{tabular}

Interpreting facts (D'angelo, 1970; Use content of knowledge to better understand Knowledge

Norling (2009) new concept

Applying generalisations (D'angelo, Use content of knowledge to better understand Comprehension 1970) new encounters

Valuing differences (Chambers, \& Feel enthusiastic with the experiences of Application Gregory, 2006) others who stay in other places or different time

Understanding important aspects of Ask questions to get information that answer Analysis life (Chambers, \& Gregory, 2006); $\quad$ or solve problems search for the meaning of life

Finding alternatives Creatively work on alternative direction of Synthesis life, and assess the implications associated with it

Differentiating between moral and immoral conducts (D'Angelo, 1970).

Recognize errors by seeking for ideas on Evaluation moral and social issues

Give attention to certain aspects of life, or ignore specific phenomena

Think of the aspects of life that deserve acknowledgement or admiration

The second pertinent question is on whether students who study English Literature would engage in simple information acquisition or complex thinking processes. It could be gathered from the above description that the learning process in English Literature class requires high level of cognitive ability, as found in the Bloom' taxonomy. Nevertheless, being in a non-native environment, the English Literature teaching is confronted with various issues, among other things involved the processing of Bloom's bottom two low-order thinking skills. It was reported by Tung and Chang (2009) that instead of focusing on critical thinking or creative thinking, the 
majority of students in Taiwan focus on improving their reading proficiency, instead of being active learners who are verbal and expressive when given critical questions by teachers. The students were found to focus on the attempt to understand of "what happened" in the text despite questioning "why or how it happened?" They fail to reflect and articulate their beliefs and actions in relation to the point they came across in the text.

The above illustration indicates that students receive less opportunity to think as their teachers assumed that students who grapple with the first two levels of the taxonomy should not be taxed with higher order thinking tasks. Case (2013) stated that this is a flaw which results from distortions to Bloom's theory in that instead of asking students to apply, analyze, synthesize and evaluate, the students are merely asked to recall, although the objective of teaching English Literature was to foster creative and critical thinking.

In short, the emphasis on the attainment of creative and critical thinking skills among student necessitates teachers to incorporate the component of thinking skills in their teaching strategies (Mahyudin, Pihie, Elias, \& Konting, 2014). If this aim is to be attained, then there are a number of prerequisites which must be satisfied, by both the teachers and students.

Students should be able to cope with higher order thinking tasks (Case, 2013). The truth is, as stated above, many Malaysian students suffer from learning difficulties in English classes especially when studying literature (Suliman \& Yunus, 2014). Students do not understand the content of literary materials, preventing them to grasp the ideas posed in the literary texts, let alone to understand beyond the described texts. They must be taught critical and creative thinking skills. Though there were views that thinking is a natural process whereby students may not need to be taught formally on the way to think (Choy \& Cheah, 2009), it is argued that formal teaching is still needed if excellence in thinking is the objective to be cultivated (Duron, Limbach, \& Waugh, 2006).

With regard to the teachers, they should adopt effective approach of teaching thinking. An individual's cognitive process is the function of his or her environment, especially that of what he or she receives from the formal education process. Nevertheless, it has been reported that many teachers admitted their unpreparedness to teach English literature (Suliman \& Yunus, 2014). They should have the sensitivity towards the learning needs of students whose mother tongue is not English language. More importantly, teachers should be cautious with the aim of curriculum which stresses on the attainment of Higher Order of Thinking Skills in the Bloom's Taxonomy of Cognitive Learning objectives (Malachi Edwin Vethamani, 2003). Although they may need to lessen the questions' difficulty due to students' inability to digest the question, or relate it with context (Case, 2013), they should make sure that they adjust the questions to still prompt critical and creative thinking by students (Case, 2013). They must be supportive to their students (Case, 2013) by exposing them to miscellaneous viewpoints that may change how they see the world, becoming prone to accept whatever they read or see (Breslin, 2015).

Based on the above, it could be concluded that the teaching of English Literature subject in Malaysia has a significant attempt to foster creative and critical thinking skills. Nevertheless it is doubtful of whether it involves the required aspects of creative and critical thinking components. Case (2013) said that Bloom's taxonomy "is seen to prescribe a necessary pathway for learning that requires moving up the hierarchy" (p. 4). In other words, students must master the first level before proceeding to the next one (Murphy \& O'Neill, 2010). However, according to Kagan (2005), one's loss of ability to remember does not affect his or her own intelligent quotient, as he was able to think rationally even though his episodic memory was damaged. He argues that the case proves higher-order thinking skills do not demand lower-order thinking skills. In this relation, Richard (1985) argues that Bloom has mistaken the concept of recall for the concept of knowledge. Recalling can be defined as a process of remembering information stored in one's long-term memory, and is not another method of critical thinking but a mere process of memory retrieval from the past (Klemm, 2007). In actuality, knowledge is defined as a processed information which students have achieved in the past through the process of understanding the information (Richard, 1985).

UNESCO (2004) stated that individuals use different cognitive processes at the same time without limiting it to one process only. This however requires teachers to set and ask questions which elicit responses that necessitate them to demonstrate their creative and critical thinking. In other words, the tasks and questions given by teachers must not be for the purpose of recalling information but to synthesise or analyse it.

It short, it is skeptical on the extent of students' engagement in the complex thinking processes as many of them have to dwell with simple information acquisition, reflective of their engagement in low order thinking activities as opposed to the higher order thinking which should be substantiated by their critical and creative thinking abilities. 


\subsection{Teaching Creative and Critical Thinking: The Importance of Incorporating More than Thinking Objectives in Teaching and Learning Taxonomy e.g. Creativity, Religiosity, Culture}

The Taxonomy of Educational Objectives has been an influential framework in the field of education. Wineburg and Schneider (2010) viewed the Bloom pyramid as somewhat giving wrong message about the importance of knowledge in learning. Though knowledge is a prerequisite to critical thinking, it is not the ultimate aim of education process. In this regard, Richard (1985) states that Bloom's taxonomy indicates "the attempt to be "value neutral" which is impossible and incompatible with the values presupposed in critical thinking education". Students are not encouraged to question what their teachers teach them in the classroom, contradicting to what the critical thinking movement advocates, that it is a taboo for students to blindly accept information. To add, teachers do not know students' thinking skills either they are able to relate their knowledge with the reality or they just memorize them in order to prepare for a test. Teachers should encourage their students to think rationally with the aim to reason out of what is right and wrong with their own thought.

The Malaysian education system adopts a holistic educational approach, characterized by a continuous effort to develop individuals who have balanced intellectual, spiritual, emotional and physical capacities. As such, the education authority in Malaysia has designed series of development and transformation plan with the aim of equipping students with desired competencies. It is expected that education system in Malaysia would be able to produce able citizens for the multi-racial Malaysia, whose progress and advancement are the results of its education system.

An important agenda in the new education system is the redefinition of student assessment and its methods, evident in the introduction of School-based Assessment (SBA). It was implemented in 2011 at primary school level, and in 2012 at secondary school level. SBA focuses on the integration of students' performance on various learning components. The philosophy and objective of SBA requires holistic students' learning objectives. Teaching in SBA framework should be regarded as a process to educate, train, mould, or edify students while assessment is not a process to measure what they have acquired or memorized but medium to foster higher order thinking among students. In SBA, examination is not the only method to measure a student's intellectual ability. SBA is a developmental tool which promotes the use of various assessment methods that give the opportunities for students to apply critical and creative thinking.

It was also reported that teachers are encouraged to teach their students through direct transfer of information without requiring them to apply critical thinking. At this point, students are only taught how to remember rather than understanding what they learnt. Othman \& Mohamad (2014) argue that teachers only accentuate on the comprehension of the subject matter even though they perceive that they are encouraging critical thinking in the classroom. The idea which states that creative and critical thinking depends on lower-order thinking skills is a misconception for in doing the higher order thinking, an individuals should be equipped with other than cognitive domains, including the affective and psychomotor domains.

In, short we are of the view that the use of Bloom's Taxonomy of Cognitive Learning Objectives is not in tandem with the Philosophy of Education in Malaysia as it appears to adopt atomistic orientation due to its thinking-centric taxonomy which actually gives much emphasis on recalling information instead of nurturing higher-order thinking skills. In fact, the effective approach to teaching creative and critical thinking warrant for use of other taxonomies which domains comprise other than the cognitive learning domains.

\subsection{Required Components of Learning Objectives, in Order to Formulate an Alternative to Bloom's Taxonomy}

The preceding sections have identified a number of issues. Firstly, the learning of English Literature involves the processing of Bloom's bottom low-order thinking skills, being aware that students are non-native English speakers who live in non-English speaking environment. The teaching and learning of English Literature should foster creative and critical thinking skills instead of English language proficiency.

The other issue is on the need to attain higher order thinking skills which reflect students' ability of creative and critical thinking. As such, the teaching and learning of English Literature subject require students to acquire the High Order Thinking Skills. The cognitive abilities to analyse, synthesise, and evaluate have been accorded as the higher order thinking that reflect students' creativity and critical thinking.

It was also highlighted that the ability to have critical and creative thinking require students to have more than the cognitive ability but other ability sets such as positive values, befitting the aspiration to develop holistic students. In other word, to be critical is not only to be able to ask and answer questions based on the six domains in the Bloom's Taxonomy.

The three issue lead to another set of questions which concern the learning outcomes of English Literature subject. 
Firstly, what are the salient components that substantiate the teaching of creative and critical thinking skills in English literature classes? Another pertinent question is on the reason behind equipping students with the creative and critical thinking, in that what do we expect the students to be able to do once they have developed the thinking skills. Given the notion of critical thinking underscores its role the fundamental for advanced thinking as it helps individuals to thoroughly decide of what to believe and do (Ennis, 2015), it is imperative to argue for the need to augment the existing framework of critical and creative thinking teaching. This argument, in turn, merits the need to identify the required components of learning objectives for the English Literature subjects. In addressing these questions, this paper

a. refers to the general outcomes of education. The emphasis on the aim to produce holistic students with balanced intellectual, physical, emotional and spiritual development is taken into account.

b. argues that the Bloom's Taxonomy should not be the only guide to design the curriculum for the subject.

c. reviews the concept of critical and creative thinking

Scholars have outlined several number of salient abilities of critical thinking which would enable students to accomplish a number of activities.

Table 2. Salient abilities of critical thinking

\begin{tabular}{|c|c|c|c|c|}
\hline Chance, 1986 , p. 6 & $\begin{array}{l}\text { generate and organize } \\
\text { ideas }\end{array}$ & $\begin{array}{l}\text { analyze facts, make } \\
\text { comparisons } \\
\text { evaluate arguments }\end{array}$ & defend opinions & solve problems \\
\hline Tama, 1989 & $\begin{array}{lr}\text { gather } & \text { adequate } \\
\text { supports } & \text { to } \\
\text { substantiated } & \\
\text { reasoning } & \end{array}$ & $\begin{array}{l}\text { stand on own view if } \\
\text { others' view are not } \\
\text { substantiated by } \\
\text { strong evidence }\end{array}$ & $\begin{array}{lr}\text { show unwillingness } \\
\text { to be persuaded } \\
\text { without } & \text { sound } \\
\text { supports } & \end{array}$ & \\
\hline Hicke, 1990 & evaluate what is read & & & \\
\hline Mertes, 1991 & $\begin{array}{l}\text { think based by } \\
\text { thoughtful beliefs and } \\
\text { actions }\end{array}$ & $\begin{array}{l}\text { evaluate information } \\
\text { and experiences in a } \\
\text { deliberated process }\end{array}$ & $\begin{array}{l}\text { interpret } \\
\text { information and } \\
\text { experience in } \\
\text { conscious manner }\end{array}$ & \\
\hline $\begin{array}{l}\text { Mayer } \& \\
\text { Goodchild 1990, }\end{array}$ & $\begin{array}{l}\text { think based } \\
\text { thoughtful beliefs and } \\
\text { actions }\end{array}$ & $\begin{array}{l}\text { understand and } \\
\text { evaluate arguments } \\
\text { in an active and } \\
\text { systematic process }\end{array}$ & $\begin{array}{l}\text { acknowledge that } \\
\text { there is no single } \\
\text { correct way to } \\
\text { understand and } \\
\text { evaluate arguments }\end{array}$ & $\begin{array}{l}\text { acknowledge that } \\
\text { not all attempts } \\
\text { are necessarily } \\
\text { successful }\end{array}$ \\
\hline $\begin{array}{l}\text { Scriven \& Paul, } \\
1992\end{array}$ & $\begin{array}{l}\text { gather information to } \\
\text { be processed from } \\
\text { observation, } \\
\text { experience, } \\
\text { reflection, reasoning, } \\
\text { or communication }\end{array}$ & $\begin{array}{l}\text { Conceptualise, apply, } \\
\text { analyze, synthesize, } \\
\text { and/or evaluate } \\
\text { information in an } \\
\text { intellectually } \\
\text { disciplined process }\end{array}$ & $\begin{array}{l}\text { Use information } \\
\text { which was } \\
\text { accurately observed } \\
\text { as a guide for belief } \\
\text { and action }\end{array}$ & \\
\hline Ennis, 2015 & $\begin{array}{l}\text { focus on thinking, } \\
\text { make reflective } \\
\text { thinking }\end{array}$ & analyse argument & $\begin{array}{l}\text { decide what to } \\
\text { believe or do }\end{array}$ & \\
\hline Lipman, 1995, & $\begin{array}{l}\text { think based on some } \\
\text { criteria }\end{array}$ & $\begin{array}{l}\text { think to make good } \\
\text { judgment }\end{array}$ & $\begin{array}{l}\text { Correct } \\
\text { thinking }\end{array}$ & $\begin{array}{l}\text { Be sensitive to } \\
\text { context when } \\
\text { thinking of an } \\
\text { information }\end{array}$ \\
\hline
\end{tabular}




\subsection{Marzano's New Taxonomy}

Address the shortcomings of the Bloom's Taxonomy; and help teachers to improve their students' thinking (Marzano, 2001). The model incorporates a wider range of factors that affect the ways students think. It consists of three systems and a knowledge domain which are fundamental to thinking and learning; Self System, Metacognitive System, Cognitive System, and Knowledge Domain.

1) The Self System happens when an individual decides whether to continue with the current behaviours or engage in the new activities he or she is exposed to. This involves his or her decision to prioritize which activity to be involved in. The decision is based on his or her belief about the importance of each activity that he or she is dealing with.

2) The Metacognitive System involves an individual's process to set goals for the chosen activity, and thinking on the ways to ensure that he or she can achieve the goals.

3) The Cognitive System involves an individual's thinking to understand all the necessary information gathered from source.

4) The Knowledge Domain provides the content of information which are necessary for the person to accomomplish his or her tasks, and attain the set goals.

\subsection{Structure of Observed Learning Outcomes}

Another taxonomy of assessing student's quality of learning is the Structure of Observed Learning Outcomes (SOLO) proposed by Biggs and Collins (2014). Unlike Bloom's Taxonomy, the SOLO taxonomy is an instructional and evaluative tool, which is more suitable to design the nature of instruction, and the evaluation of learning for any subjects, which are assessed through open-ended questions.

It is a model which emphasizes meaningful learning of knowledge in that students have two objectives to attain; (1) to learn knowledge, i.e data, skills, facts, and (2) to use the data, skills, i.e to explain what was learnt, to solve problem by using the knowledge.

It is a model that describes the levels of progressive complexity in students' understanding with five general stages (DeWitt, 2014). The stages are the pre-structural, uni-structural, multi structural, relational and extended abstract stages.

1) Pre-structural stage: The least sophisticated type of response when students who read and understand certain content of knowledge would give a response which is manifesting either a significant misconception of the content, or is using a preconception that is irrelevant to the content (Lister, Simon, Thompson, Whalley, \& Prasad, 2006).

2) Uni-structural stage: Students who read and understand certain content would manifest a correct grasp of some aspects of the issues they deal with without covering all aspects, hence developing the student's partial understanding of the content. In effect, when dealing with assessment or examination they will be doing "educated guess" (Lister et al., 2006).

3) Multi structural stage: This stage involves student's manifestations of their understanding of all parts of the problem. Nevertheless, they do not manifest their awareness that the parts have relationships among each other -hence cannot see a problem from a bigger picture (Lister et al., 2006).

4) Relational stage. This stage entails the ability to integrate the parts of a problem into a coherent structure. Students are expected to use that structure to solve the task which might not be necessarily the right solution, or best answer to any question. The relational response can be either correct or incorrect, and is labeled as relational because of its nature to be linking well to others and environment (Lister et al., 2006).

5) Extended abstract stages. This is the highest SOLO level, as the responses provided by students go beyond the immediate problem to be solved. They are also able to link the problem to a broader context (Lister et al., 2006). 
Table 3. SOLO taxonomy (O’neill, G., \& Murphy, F., 2010)

\begin{tabular}{lll}
\hline & Characteristic & Some Verbs \\
\hline Pre-Structural & Incompetent, nothing known about the area & - \\
Uni-Structural & One relevant aspect is known & List, Name Memorize \\
Multi-Structual & Several relevant independent aspects are known & Describe Classify Combine \\
Relational & Aspects of knowledge are interated into a structure & Analyse, Explain, Integrate \\
Extended Abstract & Knowledge is generalized into a new domain & Predict, Reflect, Theorise \\
\hline
\end{tabular}

Biggs and Collins find the first and the last stages to exist outside of the learning cycle. At the pre-structural level, one has not entered the cycle yet. This is because the development of one's learning starts from the second level to the relational level until he or she leaves the learning cycle at the extended abstract level (Kustra \& Potter, 2012).

While SOLO taxonomy is about learning and teaching, Bloom's taxonomy is about knowledge manifestation (Emeny, 2014). In Bloom's taxonomy, one may have an answer to a question but that does not guarantee the students to go deeper with their learning (DeWitt, 2014). Consequently, many teachers just abandon the level and get to the next one. Unlike Bloom's, there is actual progress in the manner of learning and teaching in all levels of SOLO taxonomy excluding the pre-structural level as a student is in a state of having no understanding of a particular task given. As the hierarchical Bloom's taxonomy needs to be revised, the SOLO taxonomy is like a journey where students cannot skip a level and jump to another. Emeny (2014) said, "It's like trying to solve a jigsaw without having the pieces" (p. 1). At this point, teachers should be sensitive in order to ensure such progression among their students either they understand the subject matter or miss the point.

\subsection{Alternative to Bloom's Taxonomy}

Taken together, the teaching and learning of English Literature requires rethinking on whether the Bloom's Taxonomy should be the only tool to design instruction, and evaluate work-related matters. The researchers argue that Bloom's taxonomy is insufficient in nurturing balanced attributes among students. It is also argued that the teaching of English Literature would be culturally irrelevant if the literary texts given to students has the content which are totally different to the Malaysian context. We again argue that if the teaching of English Literature is to nurture creative and critical thinking, the following suggestion should be considered:

$i$. Design learning outcome beyond the Bloom's taxonomy of cognitive learning. Given critical and creative thinking require more than the ability to process information but to think rationally, act purposefully, and relate content of knowledge with context, it is argued that students should have ability sets other than the cognitive ability sets. For instance, in order to differentiating between moral and immoral conducts (refer Table 1, and Figure 1), a students should have learned values and skills sets. It is found that Bloom's Taxonomy is overly focusing on the intellectual abilities while to be able to think rationally, act purposefully, and relate content of knowledge with context a student should be exposed to other abilities as well.

ii. Utilise local literary text. Besides developing the English Language competency, the use of local content in studying English literature can encourage students to increase their understanding of their own culture and local knowledge (Hazita, 2016). For instance, the Your Language My Culture Programme is a cultural based English language enrichment programme which uses readings materials that feature local culture (Zawiyah et al., 2015). Vethamani (2003) points out that for literature classes to stay relevant, eachers must be sensitive to students' needs and hence, text selection must be seriously considered and not made based on literary merit, language difficulty or complexity of the story. In other words, in the non-native English environment, it is important for the syllabus to incorporate the local values which are currently absent. The educational objectives, and the assessment of their attainment must include other essential aspects which lie in the local values and culture. In other words, teachers should be using resources with the local culture content.

The augmented taxonomy which contains holistic aims of learning outcome contains students three set of abilities, as depicted in the above table. It has taken into account ability sets extrapolated from the Malaysian Education Policy, Objectives of Teaching and Learning English Literature, Taxonomies of Educational Objectives (Bloom's, Marzano's and SOLO). 


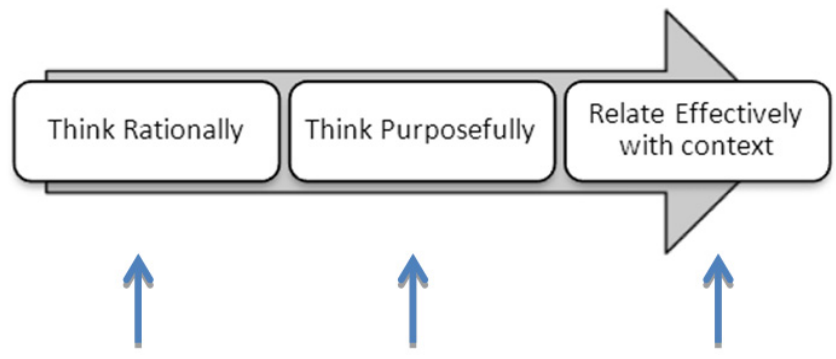

Reasoning, analyzing facts, Using a systematic and Being sensitive to context when thinking evaluating information, deliberated process

Linking thinking with spiritual defending opinions, and emotional aspects. deciding what to believe or do; correcting own thinking

interpreting information and Applying generalisations experience;

Drawing inferences

Consider the role of religion and culture in thinking processes
Expand their view of the world

deciding whether to continue current behaviours or engage in the new activities of an information

Solving problems by integrating the parts of a problem into a coherent structure, and broad context

Understanding important aspects of life

Differentiating between moral and immoral conducts

Appreciating other cultures and world views

Setting and thinking on strategies to achieve goals

Figure 1. Critical thinking in the learning and teaching of literature

\section{Conclusion}

One of the key objectives of education is to develop students' intellectual ability or thinking capacity. Students would be taught creative and critical thinking in certain subjects, including English Literature. This is particularly apt when the assessment of students' learning outcome is based on a taxonomy of learning objectives which focuses on cognitive aspects of learning, the Bloom's Taxonomy. This paper however, argues that the Bloom's Taxonomy of Cognitive Learning is not an appropriate taxonomy to design pedagogical approach for English Literature if we really want to teach creative and critical thinking. There are other criteria which need to be considered and that the whole framework of Bloom's taxonomy may no longer be relevant not only in the Malaysian context but also in the digital age in which pedagogy in teaching literature with digital natives as the targeted group, will need to be reformed.

\section{References}

Adams, N. E. (2015). Bloom's taxonomy of cognitive learning objectives. Journal of the Medical Library Association: JMLA, 103(3), 152-153. http://doi.org/10.3163/1536-5050.103.3.010

Allington, R. L., \& Strange, M. (1979). Remembering is not necessarily understanding in content areas. Reading Horizons, 20(1), 60-64.

Biggs, J. B., \& Collis, K. F. (2014). Evaluating the quality of learning: The SOLO taxonomy (Structure of the Observed Learning Outcome). New Yoyrk: Academic Press.

Bloom, B. S. (Ed.) (1956). Taxonomy of educational objectives: The classification of educational goals. Handbook I. Cognitive Domain. New York: Longman.

Breslin, F. (2015). Why public schools don’t teach critical thinking - part 1. Retrieved February 9, 2016 from http://www.huffingtonpost.com/frank-breslin/why-public-schools-dont-t_b_7956518.html

Case, R. (2013). The unfortunate consequences of Bloom's taxonomy. Social Education, 77(4), 196-200.

Chambers, E., \& Gregory, M (2006). Teaching and Learning English Literature. London, UK: Sage Publication. 
Chance, P. (1986). Thinking in the classroom: A survey of programs. New York: Teachers College, Columbia University.

Choy, S. C., \& Cheah, P. K. (2009). Teacher perceptions of critical thinking among students and its influence on higher education. International Journal of Teaching and Learning in Higher Education, 20(2), 198-206.

D'Angelo, E (1970). The Teaching of Critical Thinking Through Literature, Elementary English, 47(5), 633-637.

DeWitt, P. (2014). What's our best taxonomy? Bloom's or SOLO? Retrieved February 10, 2016 from http://blogs.edweek.org/edweek/finding_common_ground/2014/02/whats_our_best_taxonomy_blooms_or_ solo.html

Duron, R., Limbach, B., \& Waugh, W. (2006). Critical thinking framework for any discipline. International Journal of Teaching and Learning in Higher Education, 17(2), 160-166.

Elias, M. J. (2014). The importance of asking questions to promote higher-order competencies. Retrieved February 13, 2016 from https://www.edutopia.org/blog/importance-asking-questions-promote-higher-order-competencies-maurice-e lias

Emeny, W. (2014). Going SOLO on the journey towards deep learning. Retrieved February 13, 2016, from http://www.greatmathsteachingideas.com/2014/09/21/going-solo-on-the-journey-towards-deep-learning/

Ennis, R. H. (2015). Critical thinking: A streamlined conception. The Palgrave handbook of critical thinking in higher education (pp. 31-47). Palgrave Macmillan US. https://doi.org/10.1057/9781137378057_2

Hazita, A. (2016) Implementation and Challenges of English Language Education Reform in Malaysian Primary Schools The Southeast Asian Journal of English Language Studies, 22(3), 65- 78.

Hickey, M. (1990). Reading and social studies: The critical connection. Social Education, 54, 175-179.

Kagan, S. (2005). Rethinking thinking: Does Bloom's taxonomy align with brain science. Retrieved February 11, 2016, from http://www.kaganonline.com/free_articles/dr_spencer_kagan/ASK29.php

Kementerian Pendidikan Malaysia. (2014). ELEMEN KBAT DALAM KURIKULUM, Kuala Lumpur: Bahagian Pembangunan Kurikulum.

Klemm, W. R. (2007). What good is learning if you don't remember it?. Journal of Effective Teaching, 7(1), 61-73.

Lipman, M. (1995). Critical thinking - what can it be? In A. Ornstein \& L. Behar (Eds.) Contemporary issues in curriculum (pp. 145-152). Boston, MA: Allyn \& Bacon.

Lister, R., Simon, B., Thompson, E., Whalley, J. L., \& Prasad, C. (2006). Not seeing the forest for the trees: novice programmers and the SOLO taxonomy. ACM SIGCSE Bulletin, 38(3), 118-122. https://doi.org/10.1145/1140123.1140157

Mahyuddin, R., Lope Pihie, Z. A., Elias, H., \& Konting, M. M. (2004). The incorporation of thinking skills in the school curriculum. Kajian Malaysia, 22(2), 23-33.

Marzano, Robert J. Designing a New Taxonomy of Educational Objectives. Experts in Assessment. Corwin Press, Inc., A Sage Publications Company, 2455 Teller Road, Thousand Oaks.

Mayer, R., \& Goodchild, F. (1990). The critical thinker. New York: Wm. C. Brown.

Mertes, L. (1991). Thinking and writing. Middle School Journal, 22, 24-25. https://doi.org/10.1080/00940771.1991.11496002

Norling, T. (2009). Aims and objectives in the teaching of English literature at upper secondary school. Vägar till språk och litteratur, 33 .

O'neill, G., \& Murphy, F. (2010). Guide to taxonomies of learning. UCD Teaching and Learning/Resources.

Othman, N., \& Mohamad, K. A. (2014). Thinking skill education and transformational progress in Malaysia. International Education Studies, 7(4), 27-32. https://doi.org/10.5539/ies.v7n4p27

Paramjit, K., \& Nooraida, M. (2014) Examining the role of the English literature component in the Malaysian English curriculum. Procedia - Social and Behavioral Sciences, 134, 119-124. https://doi.org/10.1016/j.sbspro.2014.04.229

Potter, M. K., \& Kustra, E. (2012). A primer on learning outcomes and the SOLO taxonomy. Centre for Teaching and Learning, University of Windsor. Retrieved February 9, 2016, from 
http://www1.uwindsor.ca/ctl/system/files/PRIMER-on-Learning-

Richard, P. (1985). Bloom's taxonomy and critical thinking instruction. Educational Leadership, 42(8), 36-39.

Scriven, M., \& Paul, R. (1992, November). Critical thinking defined. Handout given at Critical Thinking Conference, Atlanta, GA.

Smith, S (2005). The reasons why a student should study English Literature, retrieved April 24, 2017, from http://www.itseducation.asia/english-literature.htm

Suliman, A., \& Yunus, M. M. (2014). A glimpse on the re-introduction of English literature in Malaysian secondary schools. International Journal of Languages and Literatures, 2(2), 151-164.

Sylvia, L., John, B., Jonathan, E., Jerry, C., \& Murali, A. (2016). Ministry Of Education: English Writing Skills Need Improvement, The Malay Mail, Retrieved April 19, 2017, From Http://Www.Themalaymailonline.Com/Malaysia/Article/Ministry-Of-Education-English-Writing-Skills-Ne ed-Improvement\#Sthash.Fljskzgw.Dpuf

Tama, C. (1989). Critical thinking has a place in every classroom. Journal of Reading, 33, 64-65.

Tung, C. A., \& Chang, S. Y. (2009). Developing critical thinking through literature reading. Feng Chia Journal of Humanities and Social Sciences, 19, 287-317.

UNESCO. (2004). Changing Teaching Practices using curriculum differentiation to respond to students' diversity, retrieved April 26, 2017 from http://unesdoc.unesco.org/images/0013/001365/136583e.pdf.

Willingham, D. T. (2012). How science can improve teaching. Retrieved February 13, 2016, from https://www.scientificamerican.com/article/how-science-can-improve-teaching/

Wineburg, S., \& Schneider, J. (2010). Was Bloom's taxonomy pointed in the wrong direction?. Phi Delta Kappan, 91(4), 56-61. https://doi.org/10.1177/003172171009100412

Zawiyah, Y., Noraini, M. Y., Noraini, I., \& Zarina, O. (2015). Your Language My Culture: Teacher Guide. Yayasan DiRaja Sultan Mizan: Terengganu.

\section{Copyrights}

Copyright for this article is retained by the author(s), with first publication rights granted to the journal.

This is an open-access article distributed under the terms and conditions of the Creative Commons Attribution license (http://creativecommons.org/licenses/by/4.0/). 